\title{
POLSKI CYCERONIANISTA ANDRZEJ FRYCZ MODRZEWSKI A ŁACINA KOŚCIELNA*
}

Andrzej Frycz hiodrzewski /1503-1572/ - to jak wiadomo, jedelı z czołowych, piszących po łacinie autorów polskiego renesansu. W jego reformatorskich 1 dydaktycznych dziełach pobrzmiewaja jeszcze pewne echa średniowiecznej scholastyici, ale jest to już twórczość bardzo renesansowa. Stanowi ona boifem odbicie czerpanej ze źódel grecko-rzymsk1ch myśli humanistycznej. Największe dzieło Modrzewskiego, traktat polityczny "De Republica emendanda", bywa rozpatrywane $z$ różnych punktóm widzenia. Jest ono interesujące także ze względów językorych. Jednyın z aspektów, w jakich można badać tę prozę łacińską są panujące powszechnie w okresie renesansu tendencje cyceroniańskie oraz ich wpływ na język 1 styl ${ }^{1}$. Literacka moda określana mianen cyceronianizmu polegała, w swej skrajnej postaci, na ścisłym i bezkrytycznym naśladowaniu Cycerona niemalże pod każdym względem. W praktyce sproradzało sie to do stosowania tylko tego słownictwa i tych konstrukcji syntakt,ycznych, jakich uśwał Cyceron. Wszelkie odstępstwa od tej reguły uchodziły za całkowity brak smaku i oznakę złego gustu.

Studiujazcy m.in. we Włosrech, podróżujacy wiele po Europie oraz utrzymujący żywe kontasty z Erazmea z llotterdalu /1467-1536/, Vivesem /1492-15.10/ czy Melanchtoneri /1497-1560/ był Modrzewski niewątpliwie pod wpływein wspomnianycin tendencji. Niemniej jednak pisał o rzeczywistości XVI w., a fakt ten pociaggał za soba konieczność adoptowania istniejącego juź słownictwa łacińskiego dla wyrażenia nowych treści czy opisyıania zjawisk nieznanych Cyceronowi 1 starożytności/chodzi tu przede wszystkim o cały świat

$x$ Artyicuz ten jest referatem wygroszonym na posiedzeniu Sekcji Filologicznej we wrześniu 1983 roku, które odbyło się $\mathrm{Za}$ kładzie Filologil Klasycznej KUL.

1 Por. T. Zielíísi, Cicero im Wandel der Jahrhunderte, Leipzig 1929. 
pojęć zwiazanych z religia chrześcijańska/. W tym kontekście nasuwają sie więc dwie zasadnicze kwest1e, na które należałoby zwrócić uwagé. Pierrsza, ściśle jezykowa, będzie polegała na llustracjl 1 analizle kllku, najbardziej zdawałoby się wymyśnych sforrułowaí, uwzglęaniającej nasze założenie - cycoronianizm a łacina kościelna, rozumiana tu jednak nie tylko jako jezzy sensu stricto, ale takze jako całe tło kulturore 1 jako rzeczywistość pozajęzykowa, która właśnie opisuje jezyl łaciríski. Druga to sposób argumentacj1, jakim najczęściej posługuje sie nasz cyceronianista. Rozpatrzenie tych dióch spraw może także stanowić jeden z pośednich sposobów na pokazanie dość ciekawego rozwoju semantycznego jezyka lacińskiego na przestrzeni wieków.

Przedstawione niżej przykłady - to pojęcia nalezące ze swej istoty do terminologii politycznej, waściwej dla dzieła "De Republica emendanda" bedacego, jak wspomniano, traktatem politycznym. Tym bardziej więc interesujący 1 godny uwagi jest lakt równoległego występowania w tym dziele np. tego samego słowa zarówno w jego znaczeniu politycznym, jak 1 religijnym z wyraźnym przesunięciem akcentu ku temu drugiemu. \$ tym miejscu należy mocno podkreślić, iz nie chodzi nam o stwierdzente, jakoby Modrzewgki Jako pierwszy nadał znanym słowom łacinskim te właśnie nowe znaczenia, bo byłoby to oczywista niedorzecznośc1a; zacytowane bowiem niżej terminy funkcjonowały w takich znaczeniach już w starożytności chrześcijańsiriej 1 we wczesnym średniorieczu /np. św. Augustyn i Civitas Dei/. Niemniej jednak uzymanie ich w dobie renesansu, zwaszcza w połączeniu z takimi imionaini, jak Christus, Deus, mogło niekiedy razić ucho słuchacza uwrazliwionego na sformułowania łaciny okresu klasycznego. Po tym zastrzeżeniu przejdźmy do analizy wybranych przykładów ${ }^{2}$.

\section{$I$}

1. Jednym z terminow politycznych występujacych w "De Republica emendanda" jest słowo "regnum". Obok czysto politycznego znaczenia Modrzewsici używał go równiez w sensie religijnym w zwrocie "Regnum Dei":

2 Teksty cytowane saz wedxug wydania: Andreae Fricil Modrevil, Commentariorum de republica emendanda libri quinque De mo- 
"At principi populi non est maledicendun, maledici enim regnum Dei non consequuntur"3.

Pozornie wydawałoby się, że wyrazenie to nie stanowi wobie niczego nadzwyczajnego. Także Cyceron uży "regna deorum"4 na oznaczenie siedziby bóstw. Kiedy Jednakze spojrzymy na to wyrazenie w całym kontekście zacytowanego fragmentu, a nawet wontekście całej religil, zobaczymy, że kryje ono głęboką 1 nową treść w stosunku do Cycerona. W ten sposób bowlem Mlodrzewski okresla zbawienie. To juz nie jest zwyczajne królestwo, w sensie terytorium czy władzy królewskiej, ale coś, co juź naleźy do rzeczywistości nadprzyrodzonej 1 co nalezy rozpatrywad w nowym chrześcijańskim wymlarze.

Podobnie drugie uzycie tego terminu w wrazeniu - "regnum Israel1s":

\footnotetext{
"Verum quia viam praeceptorum Dei feserebat ideo et Deo abiectus et regnum Israelis ab eo scissum alteri delatum, et a spiritu Dei desertus, spiritui màligno traditus est"15.
}

Znając historię Saula 1 jej szersze tło biblijne, widzimy, ze mówiąc o królestivie Izraela ma Modrzewski na myśli pewien dość szczególny rodzaj władzy wynikający ze specyficznogo charakteru narodu źydowskiego. Słowo to ponadto wzbogaciło się o nowy desygnat właśnie dzięki zestawieniu z określeniem "Israelis", a jego nowość ma swoje źródło właśnie w tym. historycznym odniesieniu do dziejóv biblijnych.

2. Innyn typowo politycznym wyrazem łaciriskim jest rzeczownik "imperium". Terminem tym okresla Modrzews'i królestwo Chrystusa:

ribus, De legibus, De bello, De Ecclesia, De schola], ed. K. Kumanieck1, Warszawa 1953.

3 De Ecclesia 5, Kumaniecki 326, 17-19.

4 Por. De repubilca I 17, 26: "quid porro aut praeclarum putet in rebus humanis, qui haec deorus regna perspexerit, aut diuturnum, qui cognoverit quid sit aeternum /.../".

De moribus 9, Kumaniecki $70,3-7$. 


\begin{abstract}
"Cur igitur nos non putawus retinendum esse Christi imperium ilsdem modis, quibus partum est?"6
\end{abstract}

Mamy tu sytuację analogiczną jak przy "regnum Dei". To z pozoru niczym nie wyróźniające się zestawiente, nabiera zupełnie nowych treści dopiero wtedy, kiedy ustawimy je na szerokim tle całej doktryny chrześcijańskiej. I dlatego właśnie, że jest ono tak odległe dla Cycerona, stanowi dla nas ciekawy przykład przesunięcia znaczenia wyrazu.

3. Nowa serie znaczeń stanowia także użycia wyrazu civitas Obok wyrażenia "civitas Dei", dobrze znanego chociaźby z dzieła św. Augustyna o tyın samyn tytule, moźna tu-przytoczyć eragment, w któryn autor "Do Republica emendanda" używa określenia - civitas Iuda":

"Sic Daviden Dei praesentia et eius beneficiorum meditatio in saltationem excitavit, dum arca Dei in c1vitatem Iuda deduceretur"7.

I tu podobnie, jak w przypadkach poprzednich, dzięki połączeniu kontekstowemu $z$,imieniel Iuda, znaczenie słowa civitas zostało zawężone tylko do tego jednejo, konkretnego miasta judzkiego. Ale nie jest to jedyna przyczyna, dla której wyrazenie to jest dla nas interesujące. Biorąc pod uwage aspekt historyczny Jerozolima to niemalze miasto symbol w religii żydowskiej. A więc słowo to oprócz desygnatu, jakim jest po prostu konkretne miasto, posiada jeszcze ten specyficzny, głębszy sens wynikający ze szczególnej roli Jerozolimy w dziejach Izraela. Na marginesie moźna jeszcze dodać, abstrahując już od określenia Iuda, że samo słowo civitas oznaczalo u Cycerona raczej państwo niż miasto/państwo oczywiście w sensie greckiego $\pi \delta \lambda_{\iota s / \text {. }}$ A zatem róźnica tkwi także w podstawowym znaczeniu pojęcia civitas.

4. Lacińskie miano princeps kojarzone i nadarane przede wszystkin władcon rzymskim, Modrzewski zastosował w stosunku do 
Chrystusa:

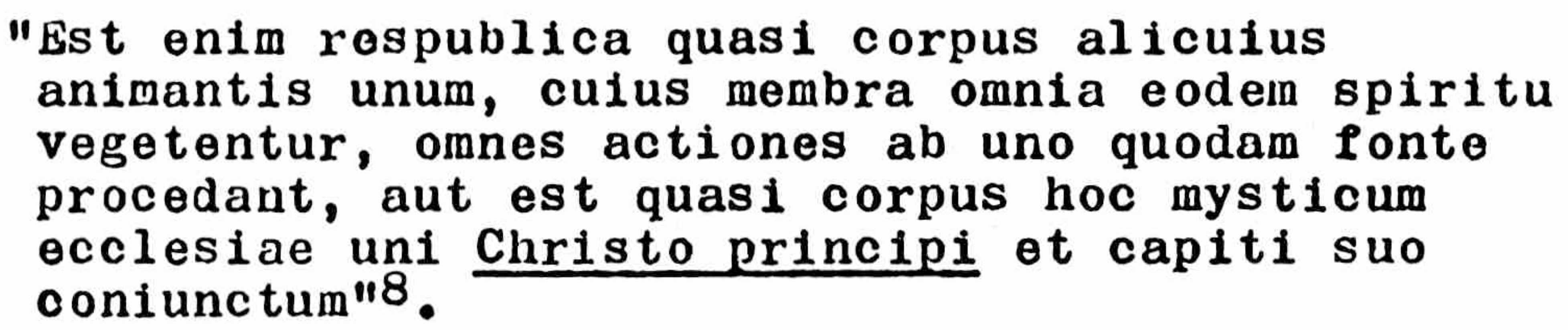

I tu znów w całym kontekście o mistycznym Ciele, którego głow̨ jest Chrystus, słowo princeps nabiera nowego, w stosunku do swoich klasycznych znaczeń, wymiaru, chociaż na pierwiszy rzut oka wydawać by się mogło, ze w zasadniczym znaczeniu tego słoia nie zaszły żadne istotne zmiany.

5. Warto przytoczyć tu także dwa dość ciekawe użycia słorra potestas, nal ėące również do dziedziny religijnej. Pod tym pojęciem kryje się u Modrzewskiego władza kapłańska, przekazana przez Chrystusa apostołom podczas ostatniej wieczerzy:

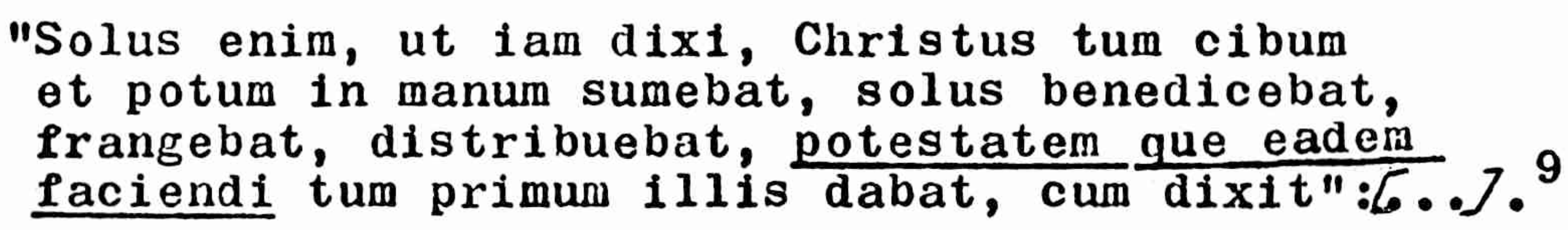

I w tym przypadku, podstawowe znaczenie wyrazu potestas nie uległo żadnej zmianie. Wzbogaciło sie jednakże o nowy odcień, nieznany zupełnie z przyczyn oczywistych Cyceronowi. Poprzez odniesienie pojęcia potestas do rzeczywistości nadprzyrodzonej, dodał mu Modrzerski piętno głębi i tajemniczości. I właśnie dzięlki włączeniu tego słowa do kręgu abstrakcyjnych pojế naszej religii, staje sie ono niejako kontrargumenten dla tezy o skrajnym cyceronianizmie Modrzewskiego, a równocześnie jednym z przykładów jego pi ̨̧knej łaciny kościelnej.

Rzeczownikien potestas określa Modrzewski takż władze papieża:

8 De legibus 21, Kumaniecki 225, 1-2.

9 De Ecclesia 19, Kumaniecki 417, 13-15. 


\section{"Quorsum enim cogitur concilium, si maior est potestas papae?"10}

Przy czym ciekawe jest tu także użycie słowa papa na oznaczente papieża, obok dobrze znanego łacińskiego wyrażenia "pontifex maxımus". Gdyby Modrzewski był radykal nym cyceronianistą, posługiwałby sie przypuszczalnie jedynie tym drugim określeniem, ponieważ użycie takie byłoby w pełni zrozumiałe, a równocześnie bardzo cycerońskie.

6. Ostatni z przykładów zwi ązany jest z rzeczownikiem plebs. Słowo to, az do naszych czasów, zachowało swoje częściowo pejoratywne znaczenie. W cytowanyin niżej Pragmencie Modrzewski używa go w sensie raczej neutralnym 1 określa nim lud świecki w odróznieniu od duchovienistria:

\footnotetext{
"Nam et plebs habet, quod exponat adversus sacerdotes et sacerdotes, quod adversus plebem, e.t utrique, quod adversus alios, a quibus putent sibi Pleri iniuriam"11.
}

W tym przypadku pole semantyczne słowa plebs zostało zawężone

a znaczenie dość wyraźnie zdeterminowane.

\section{II}

Przejdziemy teraz do przedstawienia drugiej kwestii, a mianowicle do sposobów argumentacji politycznej, stosowanych przez autora "De Republica emendanda". Dla Modrzewskiego Biblia stanowi jedyne 1 ostateczne źródło, z którego bardzo obficle czerpie argumenty na poparcie wielu szczegółowych, a jednocześnie zasadniczych dla swojego traktatu tez. Nizej przytoczymy tylko cztery wybrane fragmenty, zawierające także argumentacje biblijną. Modrzewski w swojej wizji reform stwierdza, że dobry król powinien znać przede wszystisim prawa boskie:

10 De Ecclesia 5, Kumaniecki 320, 12-14.

11 Do Ecclesia 4, Kumaniecki 313, 2-5. 
1. "Sed in primis regibus et principibus lex divina cognoscenda est, quemadmodum Moses in Deuteronomio praecipit his verbis: 'Posteaquam sederit rex in solio regni sui, legern Dei a saccrdotibus accipiat eamque omnibus diebus vitae suae legat, ut discat timere Deum et custodire praecepta eius, a quibus non declinet nec ad dextram, nec ad sinistram, ut longo teinpore regnet ipse et filii ipsius" /Deut. 17, 18-20/"12.

Idealnego władcę porównuje Modrzewski do pasterza, który troszczy się nie o sieble, ale o swoje zwierzęta. I tutaj àgumentacji dostarcza prorok Ezechiel:

2. "At pastoris est, non tam sibi quam gregi consulere, quod oraculis Dei proditum esse Ezechiel divinus vates refert his verbis: 'Vae pastoribus, qui pascunt semet ipsos; nonne greges a pastoribus pasci debent?' et cetera, quae vates copiose commemorat"/Ezech. 34, 2/13.

Uzasadniając potrzebę istnienia senatu stawia za wzór Mojzesza:

3. "Quod et Moses princeps populi Dei fecit, qui consilio Iethronis Madianitae, affinis sui, elegit multos viros principes, cum quibus potestatem suam communicaret"/Exod. 18/14.

Zacytowane wyzej Pragmenty oparte sa na Starym Testamencie, ale nie tylko on stanowi oczywíscie dla Modrzewsiciego najwyżzy autorytet. Oto przykład, gdzie przywokany jest Apostoł Paweł $i$ jedna z jego myśli:

4. "Paulus apostolus tanti facit disciplinam domestican, ut ex hac magnum sumat argumentum futuri ecclesiae episcopi. 'Quomodo enim, inquit ille, ecclesiam Dei gubernabit, qui propriae domui praeesse non novit?" /Tim. $3,5 / 15$.

12 De moribus 9, Kumaniecki $57,6-12$.

13 De moribus 9, Kumaniecki 60, 12-15.

14 De moribus 10, Kumaniecki 70, 25-27.

15 De moribus 9, Kurianiecki 69, 4-8. 
To bardzo krótkie przedstawienie wybranych z traktatu "De Republica emendanda" pojęé z dziedziny polityki wykazało znaczne poszerzenie i wzbogacenie 1ch pól semantycznych w stosunku do znaczeń klasycznych. Znane Cyceronowi łacińskie terminy polityczne, maj ace już w czasach Modrzewskiego nowe religijne znaczenie, występują w "De Republica emendanda" zarówno w jednym, jak 1 w drugim znaczeniu. Pojawiajá się także nowe użycia /np. przytoczony wyżej wyraz papa na oznaczenie papieża/. Swiadczy to, że autor nie był bezkrytycznie posłuszny tendencjom cyceroniańskim. Ciekawe zjawisko wzbogacenia semantyki politycznego właśnie słownictwa zachodzi tu w zasadzie w kontekstach biblijnych. Bardzo częste nawiązywanie do Biblii wydaje się również zasługiwać na uwage jako rodzaj swoistej deklaracji. Modrzewski nie szuka argumentów u uznanych i szeroko propagowanych w dobie renesansu autorytetów, u Arystotelesa, Cycerona czy innyci myślicieli starożytnych, ale czerpie je właśnie ze Starego $i$ Nowego Testamentu. Jest to bardzo znaczacy fakt, szczególnie jeżeli rozpatrujemy Modrzewskiego jako cyceronianistę. Jego stosunek do łaciny kościelnej wydaje się więc być jalk najbardziej pozytywny, a co wizcej, można by nawet stwierdzić, że posługuje się niaz jak godny następca Cycerona.

Nasuwa sie w tym miejscu pytanie, czy twórczość Anúrzeja Frycza Modrzewskiego nie stanowi ciekawego materialu, który można by wykorzystać w praktycznej dydaktyce języka łacińskiego. Ten godny, umiarkowany i rozsąny naśladowca Cycerona zaczerpnał z jego jezyka tylko to, co niezbędne, nie odcinając się od tradycji wypracowanej przez średniowiecze. Językiem łacińsirim W jego najpiokniejszej postaci posługuje się Modrzerski na miare potrzeb okresu, w jakim żyje oraz wymagań, jalsie stawia konkretna tematyka utworu. Wydaje się więc, że mógłby on stanowić swego rodzaju egzemplifikacje dość ciekawej ewolucji scmantycznej języka łacińskiego. Oczywiście nie jako twórca tych przemian, ale jalco kontynuator i naśladorca, a równocześnia myśliciel godzący starożytne koncepcje z myślą religijną/biblij$\mathrm{na} /$.

Jolanta Malinowska - Lublin 


\section{THE POLISH CICERONIANIST \\ ANDRZEJ FRYCZ MODRZIWSKI AND THE CHURCH LATIN /Summary/}

An article entitled "The Polish ciceronianist - Andrzej Frycz Modrzewski and the church Latin", deals with the problem of a semantic evolution of some political terms/e.g. regnum, civitas, Imperium/ used by Modrzewski in his work "De Republica emendanda". Short analysis of these words, made from the point of view of the common in Renaissance trends which required uncritical imitation of the Cicero's style, showed considerable extension and enrichment of their meanings. Hay of a political argumentation employed by Modrzewski in his treatise was the second problem considered in this article. The conclusion was that the Bible gave the most important arguments to the author. 